\title{
Anti genotoxic effect of tio2 nanoparticle biosynthesized from sargassum polycystum - a marine macroalgae
}

\begin{abstract}
Nanotechnology is the application of science and technology to control matter at the molecular level, which is also referred to as the ability for designing, production, characterization and application to structures, devices and systems by controlling shape and size at the nanometer scale The present study was an attempt to investigate antigenotoxic effect of $\mathrm{TiO}_{2}$ nanoparticle biosynthesized from Sargassum polycystum Our work aimed at conducting Genotoxicity studies for the screening of Mutagenicity using Ames test and to prove this as a antigenotoxicant. The mutagens (positive controls) treated without metabolic activation system showed a 3 fold increase of average revertant colonies per plate when compared with that of concurrent vehicle controls, thus exhibiting the ability to identify the mutagen by the tester strains. The mutagenicity assay was performed with three dose levels $(0.312,1.25$, and $5.0 \mathrm{mg} / \mathrm{ml})$ in the absence of metabolic activation system. Inhibition of background growth of non-revertant bacteria was not found at any of the three dose levels. Furthermore works are to be carried out in future to find the exact mechanism of its genoprotective nature.
\end{abstract}

Keywords: Seaweed, Ames test, Antigenotoxicity, Chromosome aberration
Volume 5 Issue 4 - 2017

\author{
Ali MS,' Anuradha V, ${ }^{2}$ Akila M,' Yogananth $\mathrm{N}^{\prime}$ \\ 'PG \& Research Department of Biotechnology, Mohamed \\ Sathak College of Arts \& Science, India \\ ${ }^{2} P G$ \&Research Department of Biochemistry, Mohamed Sathak \\ College of Arts \& Science, India
}

\begin{abstract}
Correspondence: M Syed Ali, PG \& Research Department of Biotechnology, Mohamed Sathak College of Arts \& Science, Sholinganallur, Chennai, India Email syedmicro555@gmail.com
\end{abstract}

Received: December 04, 2017 | Published: May 19, 2017

\section{Introduction}

The dramatic expansion in the nanotechnology industry over the last decade has resulted in the development of a myriad of novel materials specifically in the nano-size range (sub-100 nm). These nanomaterials (NM) are promising to revolutionise our life-style as they have unique physico-chemical features encompassing beneficial properties surpassing those of traditional substances. Such features include enhanced electrical or thermal conductivity, more efficient catalysts, high tensile strength (yet lighter weight) or improved drug delivery vehicles. Consequently, NM has potential applications in a wide range of industrial settings in addition to medical healthcare and consumer products.

In laboratory tests with Nanoparticles, the bacteria, viruses, and fungi are killed within minutes of contact. The effect of nanoparticles on bacteria is very important, since they constitute the lowest level and hence enter the food chain of ecosystem. ${ }^{2,3} \mathrm{TiO}_{2}$ nanoparticles ( $\left.\mathrm{TiO}_{2}-\mathrm{NPs}\right)$, approximately less than $100 \mathrm{~nm}$ in diameter, have become a new generation of advanced materials due to their novel and interesting optical, dielectric, and photo-catalytic properties from size quantization ${ }^{4}$ Titanium dioxide $\left(\mathrm{TiO}_{2}\right)$ is a photo catalyst and widely utilized as a self-cleaning and selfdisinfecting material for surface coating in many applications. Titanium dioxide has a more helpful role in our environmental purification due to its nontoxicity, photo induced super-hydrophobicity and antifogging effect. ${ }^{5}$ The biomedical applications of $\mathrm{TiO}_{2}$, which includes the photodynamic therapy for cancer treatment, drug delivery systems, cell imaging, biosensors for biological assay, and genetic engineering. The major advantage of $\mathrm{TiO}_{2}$ is that it is retained for a longer time within biological systems and they are nontoxic and stable without light irradiation.

Genotoxicity describes the property of chemical agents that damages the genetic information within a cell causing mutations, which may lead to cancer. Genotoxicity studies is to investigate the potency of a compound to interact with the genetic constitution. A modification of the genetic code via gene mutations (point mutations) or DNA strand breaks may lead to fundamental changes in the behaviour of bacteria and cells. In evolution these changes can be of advantage for the species, or these changes may cause diseases in vertebrates. Genetic toxicity testing is routinely performed to identify potential genotoxic carcinogens and germ cell mutagens. ${ }^{6}$ Exposure to genotoxic chemicals that are present in food, environment and also in medical treatments can alter the genetic material permanently and thus may lead to cancer. Antigenotoxic compounds from medicinal and aromatic plants are used over several years. The studies of this type are aimed at understanding the protective mechanisms which may be relevant for the primary prevention of cancer and other mutation related diseases. Plant-derived phenolic compounds exert anti genotoxic property. Antigenotoxic plant extracts can encounter or prevent the adverse effects caused by DNA damaging chemicals. This is due to the fact that dietary intake of phytochemicals has shown protective effect against the dreaded disease. Since many of the marine phyto-resources derived bioactive compounds can combat such mutagenic effect, screening of antigenotoxic potential of marine maroalgae is now gaining importance. Sargassum species are found throughout tropical and subtropical areas of the world and are reported to produce metabolites of structural classes such as terpenoids, polysaccharides, polyphenols, sargaquinoic acids, sargachromenol, plastoquinones, steroids, glycerides etc., which possesses several therapeutic activities. As it possesses many pharmacological properties, it has been considered as a medicinal food of the twentyfirst century, and research is being carried out on it to reveal its other pharmacological properties.

The common edible brown seaweed Sargassum polycystum (C. Agardh) (SP) reportedly alleviated hyperglycaemia and dislipidemia in diabetic rats, ${ }^{7}$ possibly due to its good antioxidant and free radical scavenging properties. ${ }^{8} \mathrm{SP}$ is reportedly used for eczema, scabies, and psoriasis, ulcer and lung diseases, renal dysfunction, viral hepatitis and heart ailments and to promote bile secretion, ${ }^{9}$ besides having 
antilipidemic, antioxidant and membrane stabilizing properties..$^{10,1}$ SP also has drug metabolizing enzymes protective effects, prevents TNF- $\square$ elevation, ${ }^{12}$ inhibits lipid peroxidation, and preserves hepatic antioxidant defence system in vivo. ${ }^{13,14}$ It was reported to be hepatoprotective under high-fat/highcholesterol diet. ${ }^{15}$

However, Antigenotoxic potential of this species was yet to be explored. Hence, the nontoxic and highly stable charateristic of $\mathrm{TiO}_{2}$ nanoparticle mooted us to investigate antigenotoxic effect of $\mathrm{TiO}_{2}$ nanoparticle biosynthesized from Sargassum polycystum.

\section{Materials and methods}

The species of brown algae Sargassum polycystum were collected from Mandapam, South Coast of Tamilnadu, India. The algal materials were washed thoroughly with distilled water to remove debris and other associated biota. The samples were shade dried, powdered and stored at $4{ }^{\circ} \mathrm{C}$ for further use. The dried algae of $S$. polycystum were washed several times with distilled water to remove the waste materials. $5 \mathrm{~g}$ of thoroughly washed and boiled in $100 \mathrm{~mL}$ doubledistilled water for $15 \mathrm{~min}$. Filtered algae extract was stored at $-15^{\circ} \mathrm{C}$ for further use, being usable for several weeks

\section{Green synthesis of $\mathrm{TiO}_{2}$}

Titanium tetra iso propoxide [1.5N] was dissolved in $100 \mathrm{ml}$ of distilled water for synthesis the $\mathrm{TiO}_{2}$ nanoparticles. The algal extract is added drop wise under constant stirring in the ratio of $1: 10[\mathrm{v} / \mathrm{v}]$. The mixture was subjected to constant stirring for 24 hours continuously at room temperature using orbital shaker. In this process formation of nanoparticles were observed by the formation of tiny coarse particles. The biosynthesized nanoparticles were filtered using what man filter paper and washed with distilled water repeatedly to remove the byproducts. The obtained wet nanoparticles were dried at $80^{\circ} \mathrm{C}$ overnight for the removal of moisture.

\section{Characterization of synthesized $\mathrm{TiO}_{2}$ nanoparticles from S. polycystum}

The initial spectral characterization of the biosynthesized $\mathrm{TiO}_{2} \mathrm{NP}$ was carried out after $24 \mathrm{hrs}$ between $300 \mathrm{~nm}$ to $800 \mathrm{~nm}$ using PerkinElmer lambda $25 \mathrm{UV}$-Vis spectrometer. The absorbance was taken after 5-fold diluting the sample with distilled water against distilled water as blank. FTIR was used to identify the possible functional groups responsible for the reduction of the metal ions and capping of the bioreduced $\mathrm{TiO}_{2}$ nanoparticles. The samples were analyzed on a ABB Horizon MB 3000 spectrum instrument in the diffuse reflectance mode operation with the scanning range of $4000-400 \mathrm{~cm}^{-}$ ${ }^{1}$ at a resolution of $0.7 \mathrm{~cm}^{-1}$ utilising the DTGS [Deuterium Triglyane sulphate] detector. In order to obtain good signal/noise ratio 512scans were recorded. The peaks obtained were plotted as \% transmittance in $\mathrm{Y}$ axis and wave number $\left(\mathrm{cm}^{-1}\right)$ in $\mathrm{x}$ axis. Combined with the intuitive Horizon MBTM FTIR software, the MB3000 will facilitate easy acquisition, processing and analysis of samples. Scanning Electron Microscopy is done for revealing the surface morphology of particles. Structural studies of $\mathrm{TiO}_{2}$ NPs were done by AURIGA- Cross beam FESEM (M/s Carl Zeiss, Germany). The characterization of the purified nanoparticles were conducted with an XRD 6000 X-ray diffractometry (shimadzu, Japan) operated at voltage of $40 \mathrm{kV}$ and current of $30 \mathrm{~mA}$ with $\mathrm{cu} \mathrm{k}$ radiation in $\theta 20$ configurations. The crystallite domain size was calculated from the width of the XRD picks by assuming that they were free from non uniform strains and using the sherrer formula:

$$
D=\frac{0.94}{\beta \operatorname{Cos} \theta}
$$

Where the $\mathrm{D}$ is the average crystalline domain size perpendicular to the reflecting planes, $\lambda$ is the $\mathrm{X}$-ray wave length, $\beta$ is the full width at of maximum (FWHM) and $\theta$ is the diffraction angle. To eliminate the additional instrumental broadening, the FWHM was curetted using FWHM from a large grained Si sample. $\beta$ corrected $=($ FWHM2 sample - FWHM2n) $1 / 2$ This modified formula is valid only when the crystallite size is smaller than $100 \mathrm{~nm}$.

\section{Ames test}

Cells were treated with various concentrations of Ti-NPs as described in the toxicological study. Mutagenicity was assessed by the pre-incubation assay as described by Maron and Ames. ${ }^{16}$ Briefly, $100 \mu \mathrm{L}$ of overnight cultures $(1-2 \times 108 \mathrm{cfu} / \mathrm{mL})$ of strain TA98 were treated separately for 30 minutes at $37^{\circ} \mathrm{C}^{8}$ with various concentrations of Ti-NPs in the absence or presence of S9 mix. The Ti-NPs were suspended in sterile DW and were used at a final concentration of less than $5 \%(\mathrm{v} / \mathrm{v})$. For the Ames test, the controls and Ti-NP-treated cells were mixed with $2 \mathrm{~mL}$ of sterile top agar $(0.6 \%$ agar and $0.5 \%$ $\mathrm{NaCl}$ containing $0.5 \mathrm{mM}$ histidine and $0.5 \mathrm{mM}$ biotin) and poured onto minimal glucose agar plates $(1 \times$ Vogel-Bonner salts $(0.2 \mathrm{~g} / \mathrm{L}$ magnesium sulfate, $2 \mathrm{~g} / \mathrm{L}$ citric acid monohydrate, $10 \mathrm{~g} / \mathrm{L}$ dipotassium hydrogen phosphate, and $3.5 \mathrm{~g} / \mathrm{L}$ sodium ammonium phosphate), $2 \%$ glucose, and $1.5 \%$ agar). The plates were then incubated at $37^{\circ} \mathrm{C}$ for 48 hours, after which revertants and surviving colonies were counted. Three independent experiments were conducted and each experiment consisted of three replicate plates for each treatment. The positive control used in the presence of S9 mix was 2-aminofluorene.

\section{Plating procedures}

These procedures were used in the dose range-finding and mutagenicity assays. Each plate was labeled with the test item, test phase, tester strain, activation condition, and dose. Treatments in the absence of S9 were performed by adding $100 \mathrm{ml}$ tester strain and 100 $\mathrm{ml}$ test or control article to $2.5 \mathrm{ml}$ molten diluted top agar (maintained at $45 \pm 2^{\circ} \mathrm{C}$ ). The mixtures were vortexed and overlaid onto the surface of bottom agar dishes. After the overlay solidifies; the plates were inverted and incubated for $72 \mathrm{hrs}$ at $37 \pm 2^{\circ} \mathrm{C}$. After incubation the plates were evaluated for the condition of the background lawn for the evidence of cytotoxicity and test item precipitate in comparison with the control and the plates were evaluated for the number of revertant colonies.

\section{Human lymphocytes culture and chromosal aberration studies}

Heparinized blood samples $(0.5 \mathrm{ml})$ was collected from healthy individuals and were placed in sterile culture flasks with $0.7 \mathrm{ml}$ of RPMI1640 supplemented with fetal bovine serum $(1.5 \mathrm{ml})$, antibiotic-antimycotic mixture $(1.0 \mathrm{ml})$, phyto haemagglutinin $(0.1$ $\mathrm{ml})$. The cultures are placed in incubator at $37^{\circ} \mathrm{C}$ for $24 \mathrm{~h}$. After 48 $\mathrm{h}$ incubation, test compound (biosynthesis $\mathrm{TiO}_{2}$ ) / positive mutagen of known concentration prepared in suitable vehicle or as such, will be added to the culture at a volume of $0.1 \mathrm{ml}$ to achieve desired final concentration after all other constituents, if any, are added. Negative control cultures received vehicle-DMSO alone at a volume of $0.1 \mathrm{ml}$. Negative control culture without metabolic activation will receive only $0.5 \mathrm{ml}$ of phosphate buffer. The vials/centrifuge tube/flasks will be transferred to $\mathrm{CO}_{2}$ incubator. The culture will be incubated at 37 $\pm 1^{\circ} \mathrm{C}$ and $5 \% \mathrm{CO}_{2}$ for 3-6 h. flasks were transferred to labeled sterile $15 \mathrm{ml}$ centrifuge tubes, centrifuged at room temperature at $1600 \mathrm{rpm}$ for 5-10 min, supernatant will be aspirated gently and to the pellet a freshly made working growth medium RPMI 1640 without PHA-M were added. The total volume of the culture will be made up to 10 
$\mathrm{ml}$ using the culture medium. The centrifuge tubes were transferred to $\mathrm{CO}_{2}$ incubator. The culture will be incubated at $37 \pm 1{ }^{\circ} \mathrm{C}$ and $5 \%$ $\mathrm{CO}_{2}$ for $18-21 \mathrm{~h} .100 \mu \mathrm{l}$ of $10 \mu \mathrm{g} / \mathrm{ml}$ of colchicine and incubate for additional 2 hours. The entire content of the flask was transferred to a sterile centrifuge tube and centrifuged at 800-1000rpm for 10 minutes. The supernatant was discarded and the pellet was suspended in $5 \mathrm{ml}$ of hypotonic $0.075 \mathrm{M} \mathrm{KCl}$ solution and incubated in a water bath at $37^{\circ} \mathrm{C}$ for $15-20$ minutes. The equal amount of freshly prepared ice cold fixative were added (Acetic acid: methanol, 1:3 parts). The cells were centrifuged at $800-1000 \mathrm{rpm}$ for $10 \mathrm{~min}$. The fixative was removed by centrifugation and this process is repeated twice. The slides were prepared and they were stained with $3 \%$ Giemsa stain solution in phosphate buffer (pH 6.8) for 15 min. At least 300 metaphases were scored in each slide for examining different types of abnormality according to standard protocol of Savage. ${ }^{17}$ Mitotic index (MI) was calculated by using formula, $\mathrm{MI}=$ number of dividing cells/ total number of cells $\times 100$, where MI, Mitotic index.

\section{Statistical analysis}

The Mean and standard deviation was calculated for each parameter. The data was analyzed by 'SPSS 17.0' software. Two ways ANOVA was performed to determine significance of treatment. The mean separation was performed according to Duncan's New multiple range test $(\mathrm{P} \leq 0.05)$.

\section{Result and discussion}

The use of plant based natural products as chemopreventive agents is drawing a lot of attention and considered to be practically beneficial in certain cell/tissue based systems and animal model systems. It is necessary to provide scientific proof to justify the use of a plant or its active principles for medicinal purposes. ${ }^{18}$ Modern drugs, plants and plant extracts must be characterized after their pharmacological screening for their pharmacokinetic and pharmacodynamic properties, including toxicity. A large number of potential chemopreventive agents have been identified, and they function by mechanisms directed at all major stages of carcinogenesis. ${ }^{19}$ The absorption or reflectance in the visible range directly affects the perceived color of the chemicals involved. In this region of the electromagnetic spectrum, molecules undergo electronic transitions. It is based on the principle that molecules containing $\pi$-electrons or non-bonding electrons (n-electrons) can absorb the energy in the form of ultraviolet or visible light to excite these electrons to higher anti-bonding molecular orbitals.

Characterization process of $\mathrm{TiO}_{2} \mathrm{NPs}$ includes UV-Vis absorbance measurement. $\mathrm{TiO}_{2} \mathrm{NP}$ dispersed in lake water gave a near-UV absorbance peak between 280 to $336 \mathrm{~nm}$. The dynamic aggregation process of $\mathrm{TiO}_{2} \mathrm{NPs}$ was monitored using a UV-Vis spectrophotometer at $378 \mathrm{~nm}$, analyzing the sedimentation of the NPs in different water matrices. The metal particles were observed to be stable in solution even 4 weeks after their synthesis. By stability, we mean that there was no observable variation in the optical properties of the nanoparticle solutions with time.

FTIR measurement was carried out for functional molecules or constituents in the $S$. polycystum responsible for the reduction of $\mathrm{TiO}_{2}$ ions to nanoparticles and stabilizing the nanoparticles. The $\mathrm{TiO}_{2}$ nanoparticles synthesized from $S$. polycystum exhibit a lot of biomolecules which were involved in the synthesis of $\mathrm{TiO}_{2}$ process (Figure $1 \& 2$ ). FTIR shows the presence of different functional groups, which give rise to the well-known signatures in the IR region of electromagnetic spectrum. The strong and broad band observed at $3,750 \mathrm{~cm}^{-1}$ indicates the presence of polyphenolic $\mathrm{O}-\mathrm{H}$ group and primary amine $\mathrm{O}-\mathrm{H}$ band, $\mathrm{C}-\mathrm{H}$ stretching vibrations of alkanes group was formed at the absorption band at $2,230 \mathrm{~cm}^{-1}$, a narrow band at $1,638 \mathrm{~cm}^{-1}$ indicates the presence of amide I, $1,418 \mathrm{~cm}^{-1}$ corresponding to $\mathrm{C}-\mathrm{C}$ stretching aromatic ring, $\mathrm{C}-\mathrm{O}$ stretching carboxylic acid group assigned at $1,243 \mathrm{~cm}^{-1}$, the narrow peak at $1,030 \mathrm{~cm}^{-1}$ is because of the presence of $\mathrm{C}-\mathrm{N}$ stretching vibrations of aliphatic amines of proteins and $813 \mathrm{~cm}^{-1}$ is assigned to $\mathrm{S}-\mathrm{O}$ stretching of sulfonates. The weak bands at 639 and $586 \mathrm{~cm}^{-1}$ correspond to alkyl halides. This study also confirms that the carbonyl group from amino acids or proteins has stronger ability to bind metal so that the proteins or enzymes could most possibly cap the metal nanoparticles to prevent the agglomeration of the particles.

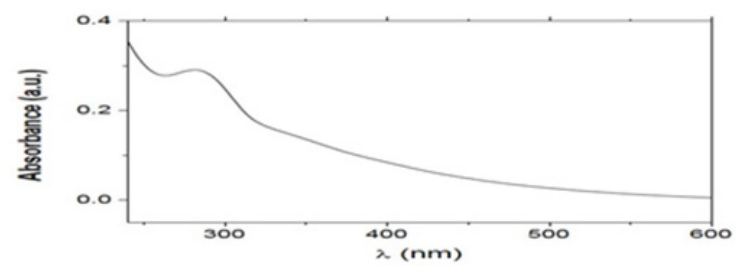

Figure I The absorbance spectrum of $\mathrm{TiO}_{2}$ nanoparticles showing maximum absorbance near $288 \mathrm{~nm}$.

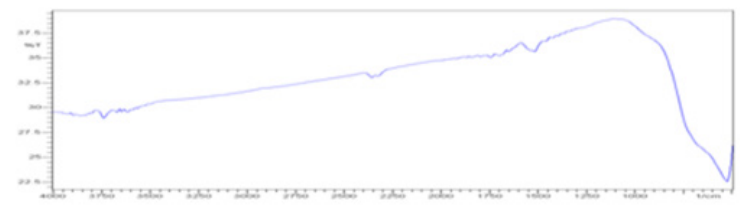

Figure 2 The FTIR absorbance spectrum of $\mathrm{TiO}_{2} \mathrm{NP}$ Biosynthesised Using S. Polycystum.

Scanning Electron Microscopy is done for revealing the surface morphology of particles. Here, the bead for the SEM analysis was prepared by placing a drop of the nanoparticle suspension on the carbon tape attached to the head of cylindrical bead and it was dried inside a vacuum dryer for a couple of hours. The particles on the top of the bead were scanned by Scanning Electron Microscope and the following image was obtained. The grain shape and surface morphology as investigated by the SEM is shown in Figure 2. The $\mathrm{TiO}_{2}$ nanoparticles were showing irregular particle structure.

Our work aimed at conducting Genotoxicity studies for the screening of Mutagenicity using Ames test and to prove this as a precursor of drug. The mutagens (positive controls) treated without metabolic activation system showed a 3 fold increase of average revertant colonies per plate when compared with that of concurrent vehicle controls, thus exhibiting the ability to identify the mutagen by the tester strains (Figure 3).

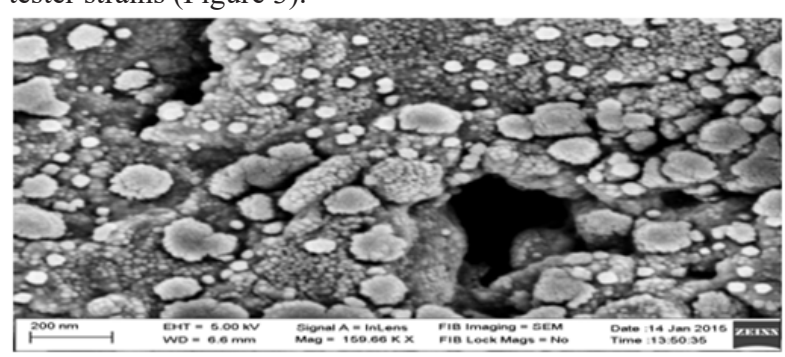

Figure 3 SEM image showing surface morphology of the $\mathrm{TiO}_{2} \mathrm{NP}$ Biosynthesised Using S. Polycystum.

The mutagenicity assay was performed with three dose levels $(0.312,1.25$, and $5.0 \mathrm{mg} / \mathrm{ml})$ in the absence of metabolic activation system. Inhibition of background growth of non-revertant bacteria was not found at any of the three dose levels. 
The study data represented in Table 1 showed no significant increase of His + revertant colonies when exposed to the biosynthesised $\mathrm{TiO}_{2}$ NPs at any of the dose levels incubated with any of the tester strains, without $\mathrm{S} 9$ addition, when compared to the respective controls in the mutagenicity assay. The average revertant colonies per plate treated with the control in the absence of metabolic activation system were found to be within the acceptance limits of the spontaneous revertant control values of respective Salmonella strains. The results showed no significant increase in the His + revertant colonies following exposure to the samples at any tested concentration in any of the tester strains without S9 when compared with the negative control of each tester strain. Based on the above results, it is concluded that the synthesised nanoparticles were non-mutagenic at the dose levels ranging from 0.313 to $5000 \mu \mathrm{g} / \mathrm{plate}$ by the Ames bacterial reverse mutation assay in the absence of S9 mix, under the conditions of the test employed.

Table I Mean Colony Count - Strain TA 98 spontaneous mutation

\begin{tabular}{lll}
\hline Test Item & $\begin{array}{l}\text { Test Concentration } \\
(\boldsymbol{\mu g} / \text { plate) / }(\mathbf{m g} / \mathbf{m l})\end{array}$ & $\begin{array}{l}\text { Histidine Revertant } \\
\text { Colonies } \\
\text { CFU/Plate }\end{array}$ \\
\hline Positive Control & Sodium azide $(\mathrm{I.5} \mu \mathrm{g} /$ plate) & 432 \\
$\mathrm{TiO}_{2} \mathrm{NP}$ & 5 & 84 \\
Biosynthesised Using & 1.25 & 60 \\
S. polycystum (without & 0.312 & 72 \\
S9) &
\end{tabular}

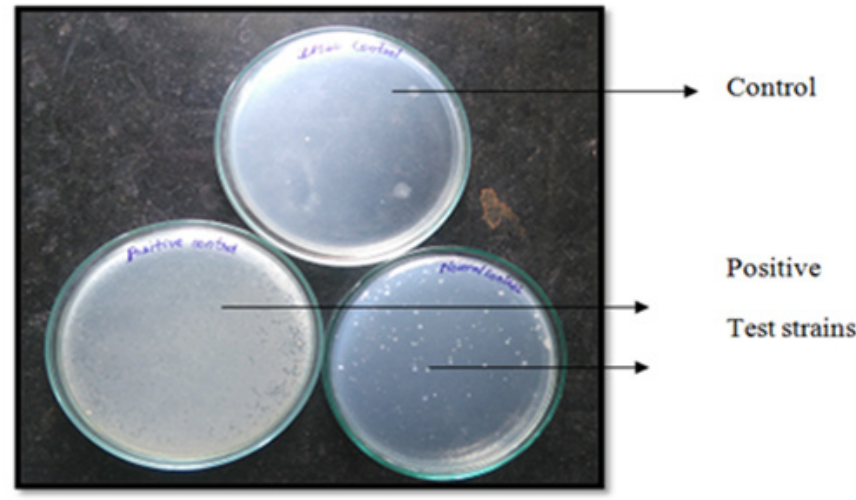

Figure 4 Normal, Positive control, DMSO for TA 98 (Set I).

When human leukocytes were treated with synthesis nanoparticle of $S$. polycystum alone at different doses; the incidence of cells having aberrants (including gap) in percentage of chromosomal aberration frequency maximum concentration of dose of 1.25 and $5 \mathrm{mg} / \mathrm{ml} \mathrm{no}$ increase in number of CA were observed when compared to untreated. In contrast, the incidence of aberrant cells in each positive control (Mitomycin C)group increased greatly as compared with each solvent group $(\mathrm{P}<0.001)$ Table 2 .

Table 2 Cytogenetic Assay of S. polycystum - Aberration Summary without S9

\begin{tabular}{|c|c|c|c|c|c|c|c|}
\hline $\begin{array}{l}\text { Dose } \\
\text { (mg/ml } \\
\text { Culture) }\end{array}$ & $\begin{array}{l}\text { Total } \\
\text { Number of } \\
\text { Cells Scored }\end{array}$ & $\begin{array}{l}\text { Percent } \\
\text { Numerical } \\
\text { Aberration }\end{array}$ & $\begin{array}{l}\text { Mean of } \\
\text { Structural } \\
\text { Aberration }\end{array}$ & $\begin{array}{l}\text { Total } \\
\text { Number of } \\
\text { Aberration }\end{array}$ & $\begin{array}{l}\text { Total no. of } \\
\text { Cells with } \\
\text { Aberration }\end{array}$ & $\begin{array}{l}\text { No. of } \\
\text { Aberration } \\
\text { per Cell }\end{array}$ & $\begin{array}{l}\text { Aberration } \\
\text { Frequency } \\
\text { (\%) }\end{array}$ \\
\hline $\begin{array}{l}\text { Negative } \\
\text { control } \\
\text { (DMSO) }\end{array}$ & 100 & 0 & 0 & 0 & 0 & 0 & 0 \\
\hline \multirow{2}{*}{0.312} & 100 & 0 & 0 & 0 & 0 & 0 & \multirow{2}{*}{0} \\
\hline & 100 & 0 & 0 & 0 & 0 & 0 & \\
\hline \multirow{2}{*}{1.25} & 100 & 0 & 0 & 79 & 6 & 13.17 & \multirow{2}{*}{10.5} \\
\hline & 100 & 0 & 0 & 73 & 9 & 8.11 & \\
\hline \multirow{2}{*}{5} & 100 & 0 & 0 & 100 & II & 9.09 & \multirow{2}{*}{20} \\
\hline & 100 & 0 & 0 & 101 & 18 & 5.61 & \\
\hline $\begin{array}{l}\text { Positive } \\
\text { control }\end{array}$ & 50 & 0 & 0 & 169 & 29 & 5.82 & \multirow[t]{2}{*}{45.5} \\
\hline Mitomycin C & 50 & 0 & 0 & 151 & 33 & 4.58 & \\
\hline
\end{tabular}

Note: The results are average of three sets of experiments. a- $\mathrm{P}<0.05$ compared to untreated, $\mathrm{b}-\mathrm{P}<0.05$ compared to Mytomycin.

Nanomedicine can be broadly defined as a technology which uses molecular tools and knowledge about human body for medical diagnosis and treatment. ${ }^{20}$ Here the nanomaterial plays the pivotal therapeutic role because of their ability to cross biological barriers. Furthermore they can stimulate self-healing cell responses and bio compatibility of implants. ${ }^{21}$ Moreover the developmental costs and risks of these materials are low as compared to other drugs. ${ }^{22}$ Ti-NPs of different sizes, shapes and material properties have many applications in various areas such as in industrial, medical and cosmetic fields. However, there is no current data on the characteristics of Ti-NPs such as size and shape in the workplace atmosphere. Many researchers have suggested that size is a critical factor for nanoparticle-induced toxicity and biological responses. ${ }^{23}$

Li et al. ${ }^{24}$ also reported that human lymphoblastoid cells exposed to $5 \mathrm{~nm} \mathrm{Ag-NPs} \mathrm{showed} \mathrm{a} \mathrm{dose} \mathrm{dependent} \mathrm{increase} \mathrm{in} \mathrm{MN} \mathrm{frequency.}$ Furthermore, Foldbjerg et al. ${ }^{25}$ reported that DNA damage was detected as an increase in bulky DNA adducts by 32P post-labeling in human alveolar cells exposed to $120-150 \mathrm{~nm}$ Ag-NPs. On the contrary, no significant genotoxic responses were observed in an Ames test $(5$ $\mathrm{nm}),{ }^{26}$ a mouse lymphoma assay $(<100 \mathrm{~nm})^{27}$ and an in vivo $\mathrm{MN}$ assay $(60 \mathrm{~nm}){ }^{28}$ The Ames test is generally used as a first screening method to assess chemical genotoxicity. In the database published by Kirkland et al. ${ }^{29} 542$ had published Ames results out of 756 rodent carcinogens. Although Ames test has proven to be invaluable in the safety testing of chemical substances, it has been less commonly used with nanoparticles. Doak et al. ${ }^{30}$ noted that 17 studies reported negative mutagenicity among the published 19 Ames test studies. In this study, the Ag-NPs were negative in the Ames test with or without S9 mix and this result are consistent with previous reports that indicated Ames tests on nanoparticles were predominantly negative. Many reasons suggested by numerous studies support that Ames test does not appear to be suitable for the assessment of nanoparticles. 


\section{Conclusion}

Nanomedicine is the phenomena which uses nanostructured or nanoscale products [size range up to $1,000 \mathrm{~nm}$ ] in medicine which have some unique medicinal properties based upon their structure. And the biological way of synthesising nanoparticles has potential applications like cost effectiveness, eco-friendly and compatibility for large scale production. In the present study the $\mathrm{TiO}_{2}$ nanoparticles biosynthesised from marine alagae extract has proved to be a powerful antigenotoxicant which is primarily due to the combined role of phenolics and flavonoids of $S$. Polysystum that initiated formation of titanium nanoparticles. However our studies are preliminary and work has to be carried out in future to find the exact mechanism of genoprotecting activity of these biosynthesised metal oxide nanoparticles.

\section{Acknowledgments}

None.

\section{Conflicts of interest}

None.

\section{References}

1. Morse MA, Stoner GD. Cancer chemoprevention principles and prospects. J Carcinogenesis. 1996;14(9):1737-1746.

2. TanakaT. Cancer chemoprevention by natural products. Oncol Rep. 1996;1(6):1139-1155.

3. Locigno R, Castronovo V. Reduced glutathione system: role in cancer development, prevention and treatment (review). Int $J$ Oncol. 2001;19(2):221-236.

4. Ohyama W, Gonda M, Miyajima H. Collaborative validation study of the in vivo micronucleus test using mouse colonic epithelial cells. Mutat Res. 2002;518:39-45.

5. Sowjanya BL, Devi KR, Madhavi D. Effects of garlic extract against the cyclophosphamide induced genotoxicity in human lymphocytes in vitro. J Enviro Biol. 2009;30(5):663-666.

6. Hayashi M, Tice RR, MacGregor JT, et al. In vivo rodent erythrocyte micronucleus assay. Mutat Res. 1996;312(3):293-304.

7. Motshakeri M, Ebrahimi M, Goh YM, et al. Sargassum polycystum reduces hyperglycaemia, dyslipidaemia and oxidative stress via increasing insulin sensitivity in a rat model of type 2 diabetes. $J$ Sci Food Agric. 2012;93(7):1772-1778.

8. Matanjun P, S Mohamed, Mustapha NM, et al. Antioxidant activities and phenolics content of eight species of seaweeds from north Borneo. Journal of Applied Phycology. 2008;20(4):367-373.

9. Jones AF, Winkles JW, Jennings PE, et al. Serum antioxidant activity in diabetes mellitus. Diabetes Res. 1988;7(2):89-92.

10. Mercuri F, Quagliaro L, Ceriello A. Review paper: oxidative stress evaluation in diabetes. Diabetes Technology \& Therapeutics. 2004;2(4):589-600.

11. Held PJ, Port FK, Webb RL. The United States renal data system's 1991 annual data report: an introduction. American Journal of Kidney Diseases. 2011;18(5):1-127.

12. West IC. Radicals and oxidative stress in diabetes. Diabetic Medicine 2000;17(3):171-180.
13. Yavuz O, Cam M, Bukan N, et al. Protective effect of melatonin on $\beta$-cell damage in streptozotocin-induced diabetes in rats. Acta Histochemica. 2003;105(3):261-266.

14. Tolman KG, V Fonseca, Tan MH, et al. Narrative review: hepatobiliary disease in type 2 diabetes mellitus. Annals of Internal Medicine. 2004;141(12):946-956.

15. Matanjun P, S Mohamed, K Muhammad, et al. Comparison of cardiovascular protective effects of tropical seaweeds, Kappaphycus alvarezii, Caulerpa lentillifera, and Sargassum polycystum, on high-cholesterol/high-fat diet in rats. Journal of Medicinal Food. 2010;13(4):792-800.

16. Hayashi M, Mac Gregor J. In vivo rodent erythrocyte micronucleus assay. II some aspects of protocol design including repeat treatments, integration with toxicity testing and automated scoring. Environ Mol Mutagen. 2000;35(3):234-252.

17. Savage JRK. Classification and relationship of induced structural changes. J Med Gen. 1979;13(2):103-122.

18. Vilar, KR Leite, L, Chen Chen L. Antimutagenicity protection of Ginkgo biloba extract (Egb 761) against mitomycin $\mathrm{C}$ and cyclophosphamide in mouse bone marrow. Gene and Mole Res. 2009;8(1):328-333.

19. Wu X, Liu H, Liu J, et al. Immunofluorscent labeling of cancer marker Her2 and other cellular targets with semiconductor quantum dots. Nat Biotechnol. 2003;21(1):41-46.

20. Sungkaworn T, Triampo W, nalakarn $P$, et al. The effects of $\mathrm{TiO}_{2}$ nanoparticles on tumor cells colonies: fractal dimension and morphological properties. Int J biomed Sci. 2007;2(1):67-74.

21. Zhang H, Chen G. Potent antibacterial activities of Ag/ $\mathrm{TiO}_{2}$ nanocomposite powders synthesized by a one-potsol-gel method. Environ Sci Technol. 2009;34(8):2905-2910.

22. Kirkland D, Aardema M, Henderson L, et al. Evaluation of the ability of a battery of three in vitro genotoxicity tests to discriminate rodent carcinogens and non-carcinogens I. Sensitivity, specificity and relative predictivity. Mutat Res. 2000;584(1-2):1-256.

23. Ames BN, Lee FD, Durston WE. An improved bacterial test system for the detection and classification of mutagens and carcinogens. Proc Natl Acad Sci USA. 1973;70(3):782-786.

24. Oesch F, Landsiedel R. Genotoxicity investigations on nanomaterials. Arch Toxicol. 2012;86(7):985-994.

25. Kirkland D, Reeve L, Gatehouse D, et al. A core in vitro genotoxicity battery comprising the Ames test plus the in vitro micronucleus test is sufficient to detect rodent carcinogens and in vivo genotoxins. Mutat Res. 2011;721(1):27-73

26. Vijaya PP, Rekha L, Anu Tersa Mathew, et al. Antigenotoxic effect of green-synthesised silver nanoparticles from Ocimum sanctum leaf extract against cyclophosphamide induced genotoxicity in human lymphocytes-Invitro. J Appl Nanosci. 2014;4:415-420.

27. Ravikumar, Murugesan Gnanadesigan. Hepatoprotective and Antioxidant Properties of Rhizophora mucronata Mangrove Plant in CCl4 Intoxicated Rats. J Exp Clin Med. 2012;4(1):66-72.

28. Jiang W, Kim BY, Rutka JT, et al. Nanoparticle-mediated cellular response is size-dependent. Nat Nanotechnol. 2008;3(3):145-150.

29. Li Y, Chen DH, Yan J, et al. Genotoxicity of silver nanoparticles evaluated using the Ames test and in vitro micronucleus assay. Mutat Res. 2012;745(1-2):4-10.

30. AshaRani PV, Low Kah Mun G, Hande MP, et al. Cytotoxicity and genotoxicity of silver nanoparticles in human cells. ACS Nano. 2009;3(2):279-290. 